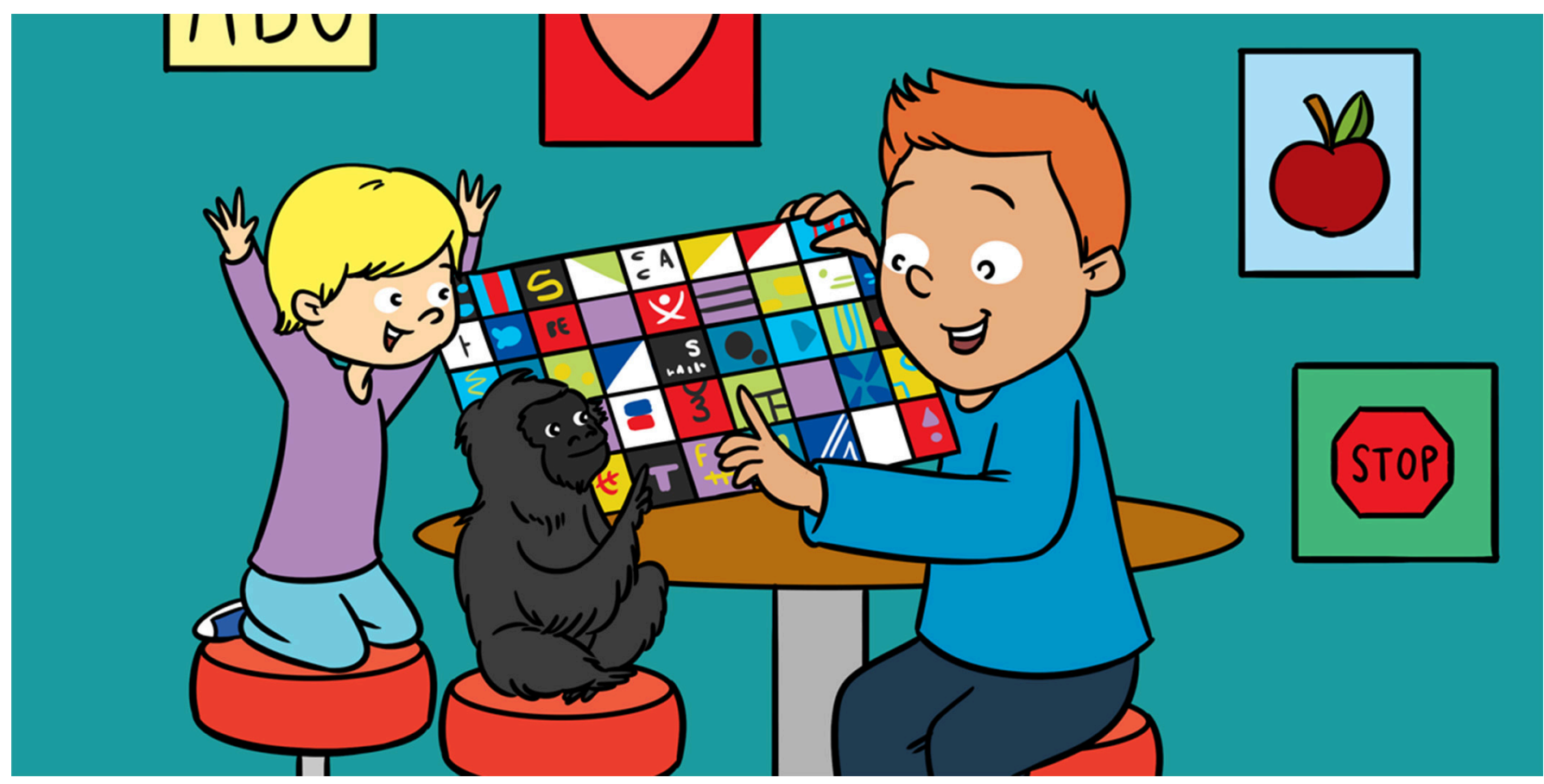

\title{
WHAT DID LANGUAGE GROW FROM? APE HANDS, MOUTHS, OR BOTH?
}

\section{Kristen Marie Gillespie-Lynch ${ }^{1 *}$, Emily Sue Savage-Rumbaugh ${ }^{2}$, Heidi Lyn ${ }^{3}$ and Patricia M. Greenfield ${ }^{4}$}

${ }^{1}$ Department of Psychology, College of Staten Island \& The Graduate Center, City University of New York, New York, NY, United States

${ }^{2}$ Independent Researcher, Springfield, MO, United States

${ }^{3}$ Department of Psychology, University of South Alabama, Mobile, AL, United States

${ }^{4}$ Department of Psychology, University of California, Los Angeles, Los Angeles, CA, United States

YOUNG REVIEWERS: ESTES

HILLS

ELEMENTARY

AGE: $9-10$
Did language grow from gestures? That is, was using the hands, arms, or head to communicate a step toward the development of language? We studied gestures and symbols used by a chimpanzee, a bonobo, and a human child who were all taught to use symbols. A symbol can be visual or spoken; the important thing is that it means something. The apes' symbols were pictures called lexigrams; the child's symbols were spoken words. The chimpanzee, bonobo, and human child used many of the same gestures. They used gestures when they were young and later added symbols. The child used her voice while gesturing more than the apes did. Our study shows that the ancestor of humans, chimpanzees and bonobos probably used gestures to communicate. Our study also shows that putting sounds and gestures together was an important skill that early humans could build on to create language over thousands of years. 


\section{Figure 1}

The Tree of Life. Image created by David Shane Smith. The Tree of Life is a map of the types of animals and other living beings in the world. Each branch of the Tree of Life represents a species. Species that are similar to each other, such as reptiles, dinosaurs and birds, or other apes and humans, are close together on the Tree of Life. Beings on the higher branches came into being after beings on the lower branches, who are their ancestors.

\section{SPECIES}

A group of animals that are similar enough to each other that they can mate and create offspring.

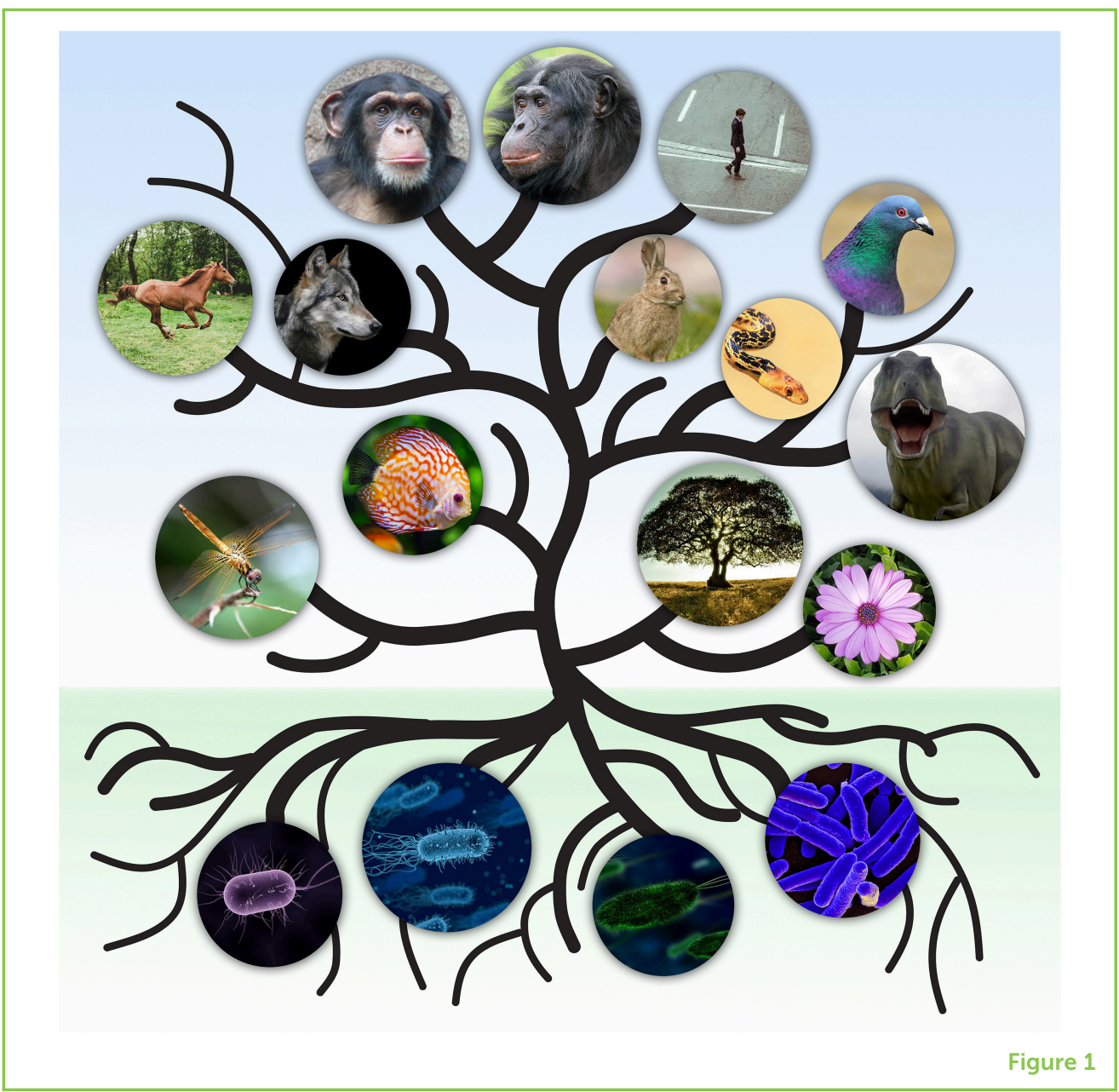

The question of how languages came into being is hard to study, because old languages do not leave skeletons behind. Luckily, baby apes hold clues about the history of language. Apes are like monkeys, but larger and without tails. Humans, chimpanzees, bonobos, gorillas, orangutans, and gibbons are all apes. Each type of ape is a species. Animals from the same species can make babies together. The other apes are closely related to people on what biologists call the Tree of Life. This Tree of Life is not a real tree. It is a map of the types of animals and other living beings in the world. The Tree of Life has so many branches on it that it looks like a tree. Each branch of the Tree of Life represents a species. Species that are similar to each other, such as dogs and wolves, deer and elk, sun fish, cat fish and gold fish, polar bears and grizzly bears, are close together on the Tree of Life. Creatures on the higher branches came into being after creatures on the lower branches, who are their ancestors (see Figure 1). The process by which a species changes over time and a new species comes into being is called evolution.

Humans and the other apes share an ancestor, which means that if you follow the branches of the generations of parents of humans and other apes back far enough, you come to the same animal (our 
shared ancestor). Humans are more like chimpanzees and bonobos than they are like the other apes, so they are closer on the Tree of Life. The three species-humans, chimpanzees, and bonobos-share an ancestor. Humans became a different species from bonobos and chimpanzees 5-7 million years ago. Bonobos and chimpanzees continued to become what they now are even after humans branched off from them. Chimpanzees and bonobos have also changed over millions of years, but in their own ways.

We can study the behavior of animals that are alive now in order to learn about the likely behavior of their ancestors. If all of the species in a branch of the tree of life can learn a skill, they probably inherited that skill from their shared ancestor. If only one species in a branch can learn a skill, the shared ancestor probably was not able to learn that skill. Instead, that one species probably developed the skill after growing apart from the other species in that branch.

Some people think humans are the only animals who can learn language. For example, many people have dogs and they know that a dog can learn to follow many commands. But following commands is not language. People use language to tell other people about things (for example, "The sky is blue." Or "The fire needs more wood.") People usually do not tell their dog such things because dogs communicate, but they do not use language like humans do. But we think that other animals, especially those that are closer to us on the Tree of Life, can learn simple language if they grow up in a home where others use language, and expect them to use language, like human children do. We think that the ancestor of humans, chimpanzees, and bonobos

\section{GESTURES}

Movements of the body used to communicate things to others. Please see another Frontiers for Young Minds article for more information about gestures: https:// kids.frontiersin.org/ article/10.3389/frym. 2018.00029

\section{LANGUAGE} EVOLUTION

The gradual development of human language over time. probably used gestures to learn language. Gestures are movements of the hands, arms, or body that are used to communicate.

\section{WHY DO WE THINK LANGUAGE GREW FROM GESTURES?}

The idea that language grew from gestures is known as the gestural theory of language evolution [1]. It is an old idea. We think that language grew from gestures because non-human apes use gestures more flexibly than they use sounds [2]. For many years, researchers tried to teach non-human apes to speak using their mouths. In 1890, a researcher taught a young chimpanzee, Moses, to say "feu" (fire in French) but Moses could not learn to say it clearly. In 1916, another researcher named William Furness tried to teach four young apes to speak. After a lot of training, one ape learned to say "cup" and "papa." But she only learned a few words. Over the next 60 years, more researchers tried to teach apes to speak by raising them with humans, but these apes only learned to speak a few words. They had great difficulty speaking words. But researchers thought that they might be able to understand many more words than they could say. 
Figure 2

A lexigram board. Lexigrams are visual symbols. Panpanzee and Panbanisha and their caregivers pointed to lexigrams on the lexigram board to share experiences and plan what to do next.

\section{SYMBOLS}

Things like words or sign language signs that stand for something else and do not need to look or sound like the thing they stand for

\section{LEXIGRAM}

Visual symbols that have a meaning and do not look like the things they stand for just like words do not need to look or sound like the thing they stand for.

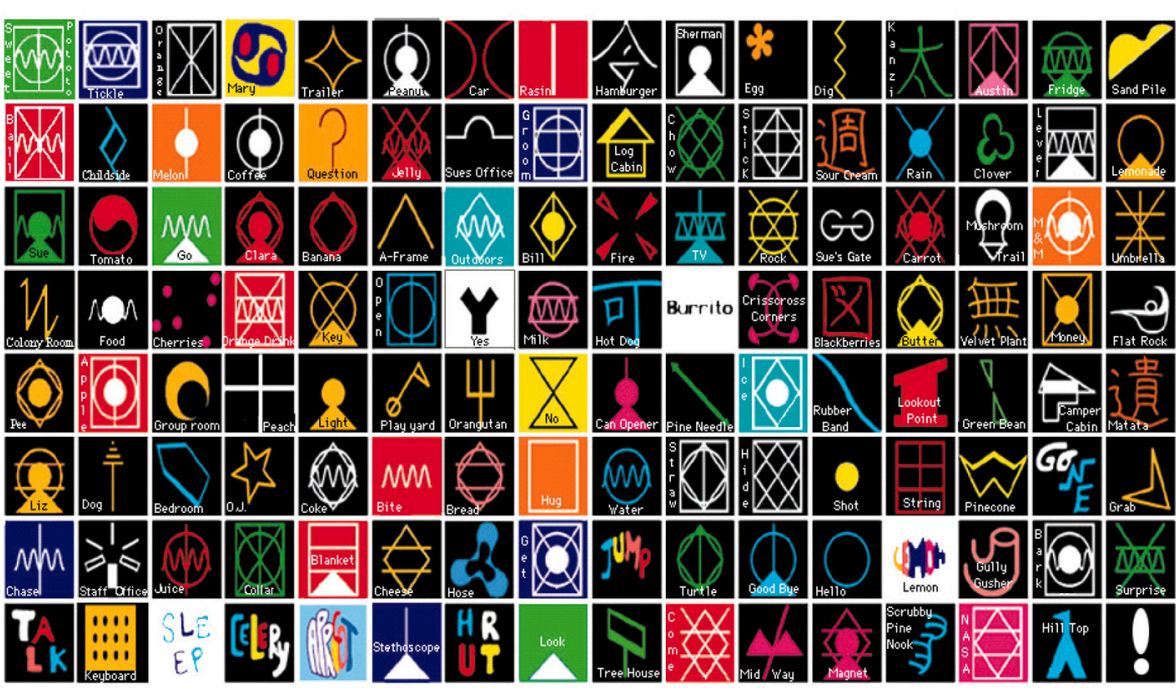

Figure 2

In 1966, two researchers named Beatrice and Alan Gardner adopted a baby chimpanzee, Washoe [3]. They thought that apes might not be able to speak very well because humans have more control of the parts of the body that we use to speak than apes do. Maybe, they thought, apes could do better with sign language. Like deaf human children, Washoe learned American Sign Language by playing with her caregivers and signing about the things they did. By the time she was 8 years old, Washoe could make around 150 signs! Each sign had a meaning, just like a spoken word. This was MANY more symbols than apes who had been taught to speak with their mouths had learned.

But chimpanzees have different types of hands than humans, which can make sign language hard for them. So, another researcher, Duane Rumbaugh, created a brand-new language for apes to use. Sign language and spoken language both use symbols, which stand for something but do not need to look or sound like the thing they stand for. Duane Rumbaugh created picture symbols (called lexigrams). Each lexigram had a meaning-it stood for a word, like "apple" or "go." Lexigrams were designed to look different from each other and different from the thing they stood for. For example, the apple lexigram was not a picture of an apple, but a rectangle with a circle and a dot (Figure 2). It was important that the lexigrams not look like the thing they stood for so they would be symbols instead of just pictures. Symbols are given their meanings by the creatures who use them, rather than by how they look or sound. For example, the words feu and fire mean the same thing, but different groups of people use different words to describe fire. Apes could point to lexigrams to express themselves. They could also understand the people around them when the humans talked with their mouths or pointed to lexigrams, too. 
Figure 3

Examples of go and up gestures.

(A) Ape

example-Panpanzee

Reach gestures to go.

(B) Human

example-Dad asks GN

if she wants pasta. She

says no and points go.

(C) Ape

example-Panbanisha (climbing on car). Sue says, "Panban, do not do that." Panbanisha gets down and comes to Sue with arm raised for up. (D) Human example-GN and Mom are playing with Lego blocks. GN raises arms up. Mom helps her up. Video frames from Gillespie-Lynch et al. [4].

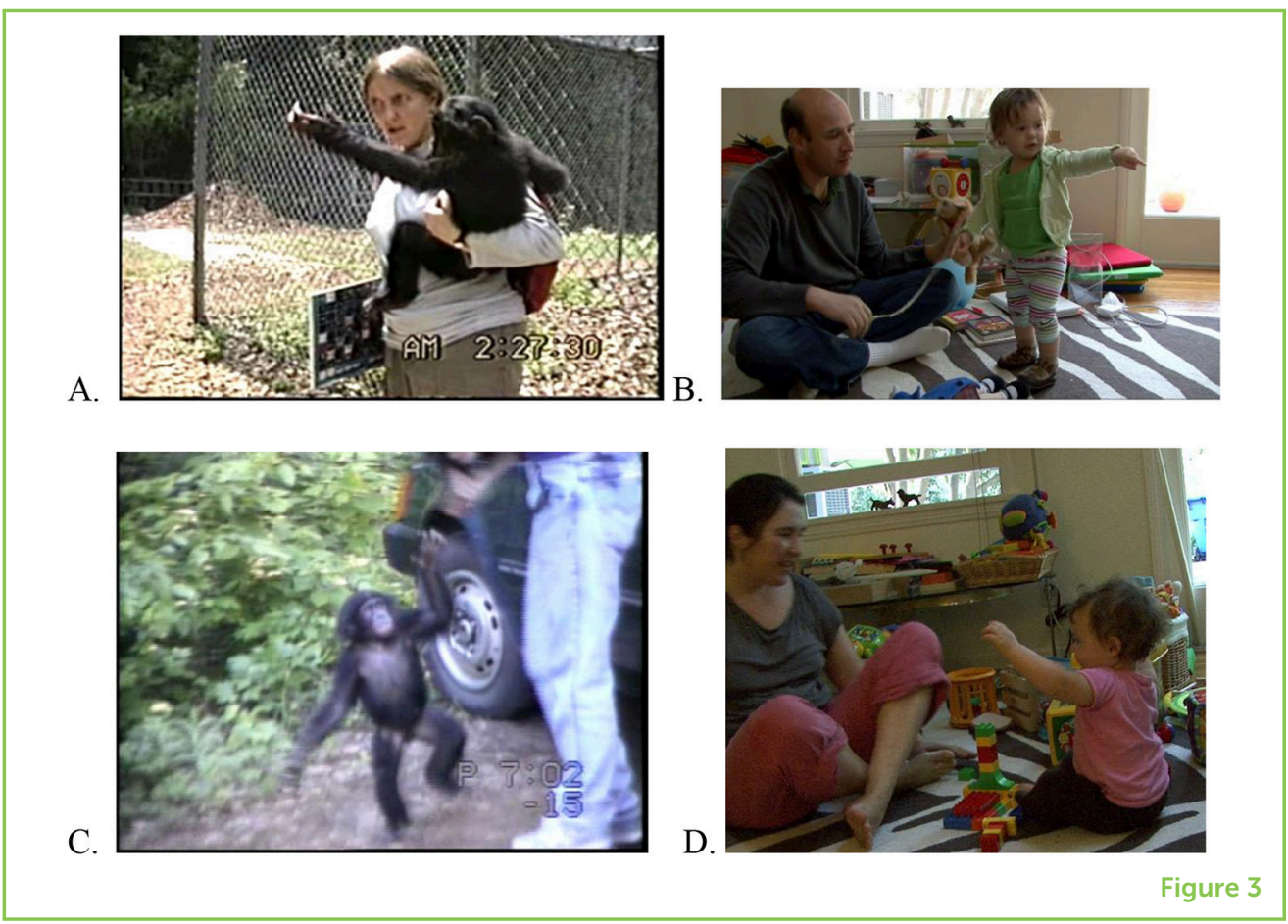

Our study [4] included a member of each of three species: a chimpanzee, Panpanzee, a bonobo, Panbanisha, and a child, GN. They were all girls. Panpanzee and Panbanisha grew up together in a home in a forest. They spent a lot of time playing with human caregivers, visiting apes who lived nearby, and traveling through the woods around their house looking for food. The apes and their caregivers used lexigrams, gestures, and speech (the apes listened but did not speak) to communicate about where they wanted to go and what they wanted to do. By communicating with the apes about things that mattered to them, the researchers helped the apes see that language is useful. Like human children, apes learn language best when they use it to communicate about things they care about with people they care about. These apes learned many ways of using language that people had thought only humans could learn, like putting symbols together to communicate new ideas [5], talking about things that are not around, and even lying!

\section{WHAT DID OUR STUDY SHOW?}

Luckily, researchers had video-taped Panbanisha, Panpanzee, and GN as they grew up. That meant we could look for and count different kinds of gestures that the apes and the child used while growing up. First, we had to define the gestures. For example, reaching is when an ape or human holds out their hand and pointing is when they point their finger toward something. So, when we saw each type of gesture, we wrote down who made the gesture, when she made the gesture, and what she made the gesture about. This procedure is called coding. Researchers use coding to turn behaviors they see on videos 
Figure 4

A comparison of types of communicative gestures/symbols across species. The $Y$ axis shows how many gestures/symbols each learner used across the time we observed them. The labels on the $X$ axis mean: Symbols (words or lexigrams), Reach Referent (reaching with their whole hand toward something), Reach Go (reaching to suggest going in a particular direction), Reach Touch (reaching toward and then touching something after the caregiver responded), Point Referent (pointing with one's index finger toward something), Point Go (pointing to suggest going somewhere), Point Touch (pointing toward and touching something), Up (raising one's arm(s) to ask to be picked up), Show (holding an object up so someone could see it), Guide Hand (moving the caregiver's hand into a reaching position), Other (gestures that did not happen very often like open: Moving a curved hand back and forth in front of a door knob). Graph from Gillespie-Lynch et al. [4].

\section{MULTIMODAL}

\section{COMMUNICATION}

Using more than one way of communicating at once, like gestures and the voice together.

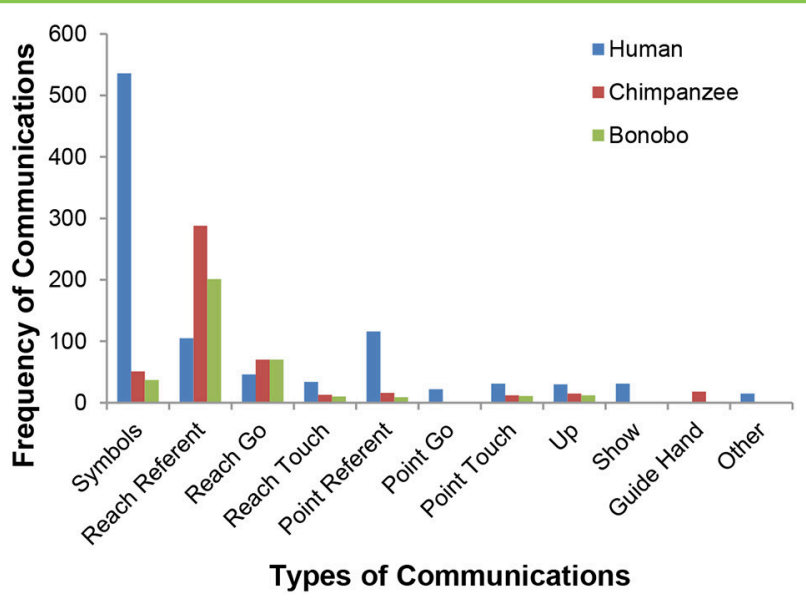

Figure 4

into numbers they can compare. We coded videos of the apes and the human from when they first used one symbol to when they started putting symbols together (starting at around 1 year of age and going to 18 months for GN or 26 months for Panbanisha and Panpanzee).

Our coding showed that Panbanisha, Panpanzee, and GN used many of the same gestures (see Figures 2, 3). In Figure 4, you can see that GN used some gestures that the apes did not, like "show" and "open." The human child also used symbols and pointed with her finger more than the apes did. The apes reached toward things they were interested in with their whole hand more than GN did. The apes and human all gestured about things in their world before they learned to communicate about them with symbols. The ape symbols were lexigrams; the human child's symbols were spoken words. All three used symbols more as they grew. Only the human child learned to use symbols more often than gestures.

\section{WHAT DO THESE FINDINGS TELL US?}

If you think that our findings support the gestural theory of language evolution, you are right! These findings tell us that the ancestor of chimpanzees, bonobos and humans probably used gestures to communicate. Our findings also provide support for a theory we did not expect: that language evolved from both gestures and sounds (which we call the multimodal theory of language evolution). The human used her voice while gesturing much more often than the apes did. Our study showed that putting sounds and gestures together (for example, pointing at a cookie and saying "eat") was an important skill that early humans could build on to create language over thousands of years.

Over a century of ape language research has provided evidence that the ancestor of humans, chimpanzees, and bonobos used gestures to build language [6]. Ape language research shows that apes can 
learn many ways of using language that people once thought only humans could learn. Our study added to research that came before it by finding evidence that language grew from the hands and mouths of our ape ancestors.

\section{ORIGINAL SOURCE ARTICLE}

Gillespie-Lynch, K., Greenfield, P. M., Feng, Y., Savage-Rumbaugh, S., and Lyn, H. 2013. A cross-species study of gesture and its role in symbolic development: implications for the gestural theory of language evolution. Front. Psychol. 4:160. doi: 10.3389/fpsyg. 2013.00160

\section{REFERENCES}

1. Hewes, G. W. 1973. Primate communication and the gestural origin of language. Curr. Anthropol. 14:5-25.

2. Pika, S. 2008. Gestures of apes and pre-linguistic human children: similar or different? First Lang. 28:116-40. doi: 10.1177/0142723707080966

3. Gardner, R. A., and Gardner, B. T. 1969. Teaching sign language to a chimpanzee. Science. 165:664-72.

4. Gillespie-Lynch, K., Greenfield, P. M., Feng, Y., Savage-Rumbaugh, S., and Lyn, H. 2013. A cross-species study of gesture and its role in symbolic development: implications for the gestural theory of language evolution. Front. Psychol. 4:160. doi: 10.3389/fpsyg.2013.00160

5. Lyn, H., Greenfield, P. M., and Savage-Rumbaugh, E. S. 2010. Semiotic combinations in Pan: a comparison of communication in a chimpanzee and two bonobos. First Lang. 31:300-325. doi: 10.1177/0142723710391872

6. Corballis, M. C. 2002. From Hand to Mouth: The Origins of Language. Princeton, $\mathrm{NJ}$; Oxford: Princeton University Press.

SUBMITTED: 15 August 2018; ACCEPTED: 18 April 2019; PUBLISHED ONLINE: 16 May 2019.

EDITED BY: Nico Sollmann, University Hospital rechts der Isar, Technical University of Munich, Germany

CITATION: Gillespie-Lynch KM, Savage-Rumbaugh ES, Lyn H and Greenfield PM (2019) What Did Language Grow From? Ape Hands, Mouths, or Both? Front. Young Minds 7:61. doi: 10.3389/frym.2019.00061

CONFLICT OF INTEREST STATEMENT: The authors declare that the research was conducted in the absence of any commercial or financial relationships that could be construed as a potential conflict of interest. 

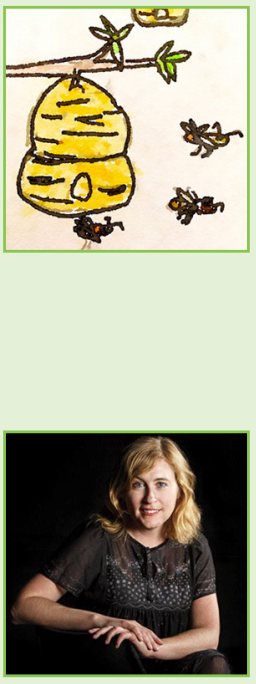

COPYRIGHT @ 2019 Gillespie-Lynch, Savage-Rumbaugh, Lyn and Greenfield. This is an open-access article distributed under the terms of the Creative Commons Attribution License (CC BY). The use, distribution or reproduction in other forums is permitted, provided the original author(s) and the copyright owner(s) are credited and that the original publication in this journal is cited, in accordance with accepted academic practice. No use, distribution or reproduction is permitted which does not comply with these terms.

\section{YOUNG REVIEWERS}

\section{ESTES HILLS ELEMENTARY, AGE: 9-10}

We are a curious class of young scientists who want to learn more about the world around us. We are learning how to think and communicate about our scientific understandings. This group of young reviewers thoroughly enjoyed being part of Frontiers for Young Minds.

\section{AUTHORS}

\section{KRISTEN MARIE GILLESPIE-LYNCH}

Dr. Kristen Gillespie-Lynch got her Ph.D. at the University of California Los Angeles, where she did ape language and autism research. She is a professor at the City University of New York where she runs a mentorship program for and with autistic college students and develops online trainings about autism to use internationally. *kgillynagmail.com

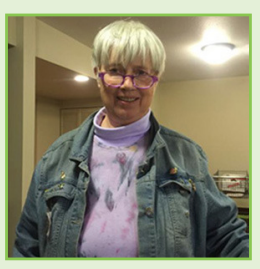

\section{EMILY SUE SAVAGE-RUMBAUGH}

Dr. Savage-Rumbaugh conducted her graduate studies at the University of Oklahoma, advised by Dr. Lemmon. More than 35 chimpanzees resided there. The cognitive and communicative differences she observed greatly influenced her career, as did the sign language work of Dr. Fouts. She designed an environment for bonobos (e.g., Kanzi and Panbanisha) and chimpanzees (e.g., Panpanzee) to allow ape and human cultures to mingle. This enabled the infants to feel secure and to acquire language by listening and observing those around them. Dr. Savage-Rumbaugh received an award as one of the 100 most influential people in the world for this work.

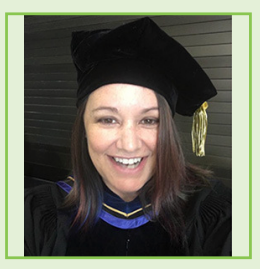

\section{HEIDI LYN}

Heidi Lyn is an Associate Professor and Joan M. Sinnott chair of Psychology at The University of South Alabama and has worked everywhere from Hawaii to Harderwijk (the Netherlands) studying animal intelligence and communication. She has published studies on cognition and communication in chimpanzees, bonobos, and dolphins, and has also studied the behavior of belugas, sea otters, and walrus.

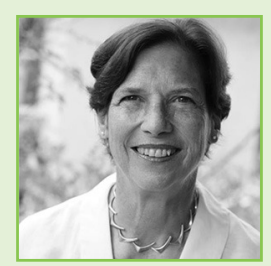

\section{PATRICIA M. GREENFIELD}

Dr. Patricia Greenfield is a professor in the Psychology Department at UCLA. She became interested in ape language when she noticed in a film that Washoe, an ape who learned sign language, was communicating in ways that were similar to the 
way her own human son communicated as he began to use language between ages 1 and 2. A few years later, she had the opportunity to collaborate with Dr. Sue Savage-Rumbaugh on her language studies with chimpanzees and bonobos. They wrote a number of articles together. Later, all four authors worked together on studies of ape language and communication. 